\title{
A SIMBOLOGIA DO IMAGINÁRIO POPULAR NAS FESTAS JUNINAS
}

\author{
*Dulcilene Ribeiro Soares Nascimento
}

\section{Resumo}

Do ponto de vista das tradições regionais brasileiras, nenhuma tem a abrangência mais especificamente no nordeste brasileiro que as festas juninas. Além do sentido cultural que envolve as tradições e o lúdico, o sentido econômico que envolve desde o turismo até a movimentação das as pequenas economias e do comércio as festas de Santo Antônio, de São João e de São Pedro, respectivamente são sem dúvida muito $\circ$ grande ponto de congregação cultural no nordeste brasileiro. Este artigo discute a importância dessas festividades desde a sua simbologia no imaginário popular até a sua influência na economia das cidades, principalmente os municípios de pequeno porte do nordeste do Brasil.

Palavras-Chave: Tradições, Festejos Juninos, Cultura, Economia.

\section{Abstract}

Of the point of view of the Brazilian regional traditions, none has the abrangency more specifically north-eastern Brazilian who the juninas parties. Beyond the cultural direction that involves the traditions and the playful one, the economic direction that involve since the tourism until the movement of the small economies and the commerce the parties of Saint Antony, of Are John and of They are Peter, respectively are without a doubt much more that the carnival the great point of cultural congregation north-eastern Brazilian. This article argues the importance of 
these festivities since its imaginary symbology in the popular one until its influence in the economy of the cities, mainly the cities of small northeast transport of Brazil.

Words Key: Traditions, Festoons Junín's, Culture, Economy.

\section{Resumen}

Del punto de vista de las tradiciones regionales brasileñas, ninguna tiene la abundancia más específicamente del noreste de Brasil que las juninas. Más allá de la dirección cultural que involucra las tradiciones y la lúdica, la dirección económica que involucran desde el turismo hasta el movimiento de las pequeñas economías y el comercio las fiestas de San Antonio, de Are John y de They are Peter, respectivamente están sin un Dudo mucho más que el carnaval, el gran punto de congregación cultural del noreste brasileño. Este artículo argumenta la importancia de estas festividades desde su simbología imaginaria en la popular hasta su influencia en la economía de las ciudades, principalmente las ciudades del pequeño transporte nordeste de Brasil.

Palabras clave: Tradiciones, Festones De Junín, Cultura, Economía.

* Dulcilene Ribeiro Soares Nascimento é PHD e Doutora em História, Mestre em Ciência Política, Cidadania e Governação, Mestre em Educação, Especialista em Metodologia do Ensino, Pesquisa com extensão em Educação e Licenciada em História.

\section{INTRODUÇÃO}

As festas juninas nascidas da tradição cristã são oriundas da e tiveram no Brasil um alcance e desenvolvimento peculiares. No Nordeste do Brasil, região talvez mais culturalmente propensa a essa atividade e onde a permanência desse traço europeu é evidente a Noite de São João pode ser comparada à do Natal, em 
termos de significado e respeito.

A tradição dos festejos no mês de junho vem de longe. Na França, no século XII, a comemoração se referia ao início do verão e das colheitas, e após algum tempo foi associada pelo catolicismo ao aniversário de São João Batista, no dia 24. No século seguinte, em Portugal, passaram a ser também homenageados Santo Antônio, no dia 13, e São Pedro, no dia 29.

O costume chegou ao Brasil nos tempos coloniais, e aqui há registros de festas desse tipo pelo menos desde 1583. Embora espalhada por todo o País, foi no Nordeste que a celebração mais se enraizou, agregando às fogueiras, que já eram comuns na Europa, algumas características novas

Em termos de consolidação dos traços culturais nacionais a importância dos festejos juninos torna-se ímpar, pois além das músicas, danças, culinária, as simbologias, como as fogueiras e os fogos, as quadrilhas, o linguajar, os significados e significantes, tudo isto forma um conjunto que caracteriza o Nordeste e o seu povo.

Espalhada por todos os municípios nordestinos, do Litoral ao Sertão, as festas juninas caracterizam a repetição das manifestações culturais que vêm mobilizando o conjunto da sociedade nordestina durante toda a sua história. Atualmente, não apenas o aporte cultural é considerado. Do ponto de vista econômico o alcance para a economia local da realização dos festejos juninos é ímpar. Alguns municípios inclusive vivem o ano inteiro em função dos preparativos que Ihes fornecerão o sustento pelo restante do ano. O turismo e o comércio de algumas cidades recebem dividendos que seriam praticamente impossíveis em outras circunstâncias.

O calendário nordestino assim tem nas festas juninas seu maior ápice porque beneficia os estados como um todo, diferentemente, por exemplo, do carnaval que atinge apenas algumas regiões, especificamente a metropolitana. Integrado à cultura popular nordestina, o ciclo dos festejos juninos ultrapassou limites e hoje é também um marco turístico e um significativo fator de incremento da economia, agregam todos os municípios, dos menores aos maiores, que além de se beneficiarem economicamente da festa, que mobiliza dezenas de setores das economias locais, beneficiando, sobretudo, os micro e pequenos comerciantes e trazem um mês inteiro de cultura, lazer e entretenimento, formando uma festa comunitária e inclusiva, além 
de gerar milhões em lucro para os grandes centros e referencias como Campina Grande na Paraíba e Caruaru em Pernambuco que disputam o título de Capital do Forró no Nordeste.

\section{FESTA E O SEU PAPEL LÚDICO-SOCIAL}

De acordo com Jean Duvignaud (1983), festas são eventos caracterizados pela produção de um tempo e de uma forma de vivência momentaneamente alternativos ao cotidiano burocratizado e normatizado pelas regras de conduta social, que também determinam uma ruptura da vida social. De acordo com antropólogo Roberto Da Matta, trata-se de uma realidade paralela e efêmera onde criam-se sujeitos ou grupos imaginários que podem ser seres míticos ou mesmo grandes personalidades; nesse contexto, um operário assalariado pode se transformar em um príncipe ou rei.

Nessa conjunção, festa se constitui em uma metamorfose transitória de papéis sociais, significando uma ruptura do cotidiano funcional, como destacam alguns autores e nesse ínterim as festas populares se constituem em uma importante manifestação cultural que pode ter sua origem em um evento sagrado, social, econômico ou mesmo político do passado e que, constantemente, passam por processos de recriações e atualizações.

Conforme Paul Claval (1999), a cultura, como herança transmitida, pode ter sua origem em um passado longínquo, isso, porém não a caracteriza enquanto um sistema fechado, imutável de técnicas e comportamentos. A concepção de cultura como sistema aberto permite a compreensão do dinamismo de algumas manifestações culturais que preservam elementos importantes e que representam a ponte entre o passado, o mito elementar e o presente.

Segundo Claval (1999) os contatos são os elementos chave para que ocorram as mudanças, transformações e reinvenções das práticas culturais, a intensificação das formas de informação e comunicação nos últimos anos atesta isso. Porém a maioria dos estudiosos na cultura entre eles Mircea Eliade (1992) e Luis da Câmara Cascudo (1969) demonstra a preocupação com a conotação mercadológica e de espetáculo que algumas festas conotam e que provocam uma 
ruptura entre o ato de festejar e a rememoração, o conhecimento histórico, um mito fundante ou mesmo uma prática de ritualização.

Hannah Arendt (2002) ressalta que o enfoque lúdico-cultural, eivado de simbolismo, se diferencia da prática festiva como entretenimento efêmero, assentado no lazer e na diversão, constituindo-se fundamentalmente em uma prática presenteista, que, em muitos aspectos, realça o passado como um pano de fundo ou na perspectiva da estetização do espaço festivo.

\section{ORIGENS E SIGNIFICADOS DAS FESTAS JUNINAS}

A sociedade é dinâmica, por isso o ato e os significados do festejar se diferenciam ao longo do tempo. Existe assim uma diferença entre as festas de rememoração, com fortes vínculos com práticas do passado, e as festas de entretenimento, cuja finalidade é promover o lazer, a diversão. A festa junina apesar de buscar a manutenção de práticas festivas rituais e ancestrais resiste em perder hoje certamente seu espaço para esse aspecto de mercado que as festas contemporâneas vêm tomando.

De acordo com o culturalista Luís da Câmara Cascudo (1969), as festas juninas brasileiras são recriações de outras celebrações europeias, em especial as portuguesas, que possuíam aspectos familiar e/ou comunitário, permeadas pelo ritualismo mítico-religioso. A exemplo disso a história de São João relembra o evento da gravidez de Isabel que de acordo com relatos bíblicos, era estéril e estava em uma idade avançada e que ainda assim engravidou e pediu que o nascimento do seu filho, o profeta João Batista fosse comunicado através de uma grande fogueira acesa.

A importância de João foi confirmada pelo próprio primo Jesus Cristo que posteriormente foi batizado por ele, ao dizer: "Na verdade vos digo que, entre os nascidos de mulher, não apareceu nenhum maior do que João, o Batista. E, se quereis aceitá-lo, ele mesmo é o Elias que há de vir. O que tem ouvidos, ouça! "(São Mateus, 11,7-11 e 14-15).

Outras versões atribuem 0 ato de se acender as fogueiras às práticas europeias pagãs de alguns povos que viam no fogo um elemento mágico para espantar as pestes da lavoura. Na dimensão mítica folclórica afirma-se que São 
João dorme no ápice profano das festas juninas. Caso acordasse e presenciasse a forma como se comemora seu nascimento, ele desceria do céu e perderia a santidade. Assim as festas juninas da Região Nordeste do Brasil são eventos predominantemente profanos, mas que têm sua origem em elementos do sagrado, reinventados pela cultura popular e redesenhados no espaço urbano.

As resistentes fogueiras que persistem desafiando os grandes espetáculos urbanos armados em grandes palcos simbolizam uma prova de que os aspectos profanos das festas de Santo Antônio, São João e São Pedro não sucumbirão. O catolicismo oficial que celebra ao trio a partir de ritos litúrgicos formais e 0 catolicismo popular que os celebra através de práticas criadas e reinventadas pelo povo ao longo do tempo demonstram isso.

O imaginário popular com suas lendas, superstições, misticismo e ritualismo têm nas festas juninas seu maior momento. O sincretismo é perfeito. Há uma sincronização de interesses e finalidades. É a celebração do lúdico, da inocência, do sentido de comunidade e compartilhamento. Tudo isso é fruto do universo simbólico ao qual vários autores interpretam como o equivalente significativos do significado. "Os costumes são dados como normas externas, antes de engendrar sentimentos internos, e essas normas insensíveis determinam os sentimentos individuais, bem como as circunstâncias onde poderão e deverão se manifestar" (Lévi-Strauss, 1958,p. 101) .

\section{A SIMBOLOGIA}

O símbolo supõe uma estrutura dupla, um representante e um representado. Nesse contexto, cultura é simbólica pois pode ser considerada como um conjunto de sistemas simbólicos, como por exemplo a linguagem, as regras matrimoniais, as relações económicas, a arte, a ciência, a religião, entre outros.

Para Berger e Luckmann (1978) os universos simbólicos são passíveis de cristalização segundo processos de "objetivação, sedimentação e acumulação do conhecimento". Esses processos de cristalização levam a um mundo de produtos teóricos que, porém, não perde suas raízes no mundo humano de tal sorte que os universos simbólicos se definem como "produtos sociais que têm uma história".

Assim, a explicação do símbolo pelo "real" é ilusória, sendo naquela 
interpretação da cultura que necessitamos instalar-nos, recusando toda e qualquer redução ao naturalismo. Por exemplo, o mito e o ritual não são para serem compreendidos em função do real, uma vez que consistem numa organização da experiência sensível no âmbito de um sistema semântico.

Assim sendo as festas juninas representam na cultura enquanto produção humana compõe um universo simbólico cuja rede de relações e significações lançam o homem num mundo codificado e repleto de referentes não-arbitrários (porque estabelecidos convencionalmente) mas cuja ambivalência (ou mesmo plurivalência) de objetos e significados são constantemente interpretados. Ora, o homem é um produtor de símbolos por excelência, já que estes são o elemento mediador entre si e o mundo.

\section{CONSIDERAÇÕES FINAIS}

Os traços da cultura brasileira por meio desses símbolos, o respeito e admiração pelas origens e ancestralidade são o que de fato sobressaem das festas juninas. Os aspectos de diversificação e modernidade que elas vêm tomando nos últimos anos certamente são ingredientes necessários à mudança que também é um elemento cultural.

O mais importante é perceber que apesar de todas os ingredientes de modernização, os aspectos míticos, religiosos, e ancestrais que tornam únicos esses festejos, destacando-se os aspectos inclusivos desses festejos que permanecem vivos no imaginário popular e esperados para serem celebrados no raiar do mês de junho, principalmente na região nordeste do Brasil. 


\section{REFERENCIAS}

ARENDT, Hanna. Entre o passado e o futuro. Tradução de Mauro W. Barbosa. São Paulo: Perspectiva, 2002.

BERGER, Peter e LUCKMANN, Thomas: "A Construção Social da Realidade: tratado de sociologia do conhecimento", trad. Floriano Fernandes, Rio de Janeiro. Editora Vozes, 1978.

BRANDÃO, Carlos. R. A Cultura na rua. Campinas: Papirus, 1989.

CASCUDO, Luís da Câmara. Folclore do Brasil: pesquisas e notas. Brasil/Lisboa: Fundo de Cultura, 1969.

Dicionário do Folclore Brasileiro. Rio de Janeiro: Ediouro, 1954.

CLAVAL, Paul. Geografia Cultural: o estado da arte. In: CORRÊA, Roberto Lobato; ROSENDHAL, Zeny (Org.). Manifestações da cultura no espaço. Rio de Janeiro: EDUERJ, 1999. p. 59-97.

DAMATTA, Roberto. A casa e a rua. Rio de Janeiro: Guanabara, 1987.

O que faz o Brasil, Brasil? Rio de Janeiro: Rocco, 1984.

DURKHEIM, Émile. As formas elementares da vida religiosa: o sistema totêmico na Austrália. Tradução: Paulo Neves. São Paulo: Martins Fontes, 1996.

DUVIGNAUD, Jean. Festas e civilizações. Tradução de L. F. Raposo Fontenelle. Fortaleza: UFCE/Rio de Janeiro: Tempo Brasileiro, 1983.

ELIADE, Mircea. O Sagrado e o Profano. Tradução de Rogério Fernandes. São Paulo: Martins Fontes, 1992. 
LÉVI-STRAUSS, C. Antropologia estrutural. Rio de Janeiro. Tempo Brasileiro. 1958.

LIMA, Elisabeth C. de Andrade. A fábrica dos sonhos: a invenção das festas juninas no espaço urbano. João Pessoa: Ideia, 2002. 